\title{
Assessment of depression severity among cancer patients in Nanakaly Hospital, Erbil City
}

\begin{tabular}{ccc}
\hline Mosleh Saber Kareem* & Yusif Bakr Omer** & Bakhtyar Othman Omer** \\
\hline & Abstract
\end{tabular}

Background and objective: Depressive symptoms are present in several psychiatric disorders, the ones most commonly seen in patients with cancer, especially more common in those who are at the end of life. This study aimed to assess the severity of depression and association between socio-demographic data with the severity of depression among Cancer Patients in Nanakaly Hospital, Erbil City. Methods: A cross-sectional study was conducted on 100 cancer patients of both genders in Nanakaly Hospital, Erbil city, Iraq, from February 22 $2^{\text {nd }}, 2016$ to April $27^{\text {th }}, 2016$. A questionnaire was designed for the study; it contained two parts. Part one consisted of socio-demographic characteristics such as age, gender, level of education, occupation, marital status, economic status, religion and residential area of the patients. Part two consisted of Beck depression rating inventory. Data were collected through interviews with patients. Frequency, percentages and Chi-square tests were used for interpretation of data.

Results: The mean age $( \pm S D)$ was 49.5 (16.66 \pm ) 4years. Each of males and females represented $50 \%$ of the sample. Most of the participants were married $(75 \%)$, illiterate $(35 \%)$, Muslims $(94 \%)$, housewives $(38 \%)$, had somehow sufficient income $(40 \%)$ and from rural areas (84\%). Majority of the studied sample $(79 \%)$ suffered from moderate depression level, while only $(21 \%)$ of them suffered from severe depression. There was no significant association between the level of depression and the socio-demographic characteristics of the patients and the medical status as well.

Conclusion: The study concluded that most of the cancer patients have depression symptoms.

Keywords: Depression; Cancer patients.

\section{Introduction}

Depressive symptoms are present in several physical disorders as cancer, especially more common in patients who are at the end of life, especially in patients who are at the end of their life. ${ }^{1}$ The study done by Takashi and Takayuki (2008) revealed that the psychiatric interview revealed that $44 \%$ of cancer patients and $38 \%$ of the medical patients had mental disorders. The most frequently observed disorder was depression. ${ }^{2}$ Depression accounts for $4.4 \%$ of the overall global disease burden, and the disability adjusted life years for depression in the near future will be greater than cancer. Depression leads to a decline in patient satisfaction with medical care and predicts disease progression; untreated depression can result in physical disability and sometimes resistance to treatment as well as having an effect on the mental and physical performance of all the family or even lead to death. ${ }^{3}$ A strong body of evidence demonstrates the coexistence of depression and cancer, reported prevalence rates of depression for tumors is ranging from 20 to $50 \%$. These results generally include all depressive disorders. Grassi et al. found that out of 201 recently

* Department of Psychiatric Nursing, College of Nursing, Hawler Medical University, Erbil, Iraq.

** Department of Adult Nursing, College of Nursing, Hawler Medical University, Erbil, Iraq. 
diagnosed cancer patients, $15 \%$ met the criteria for a major depressive disorder. There is a reason to believe that many patients affected by subclinical depression go undetected. ${ }^{4}$ Depression remains over looked and undertreated in the hospitals, despite their prevalence and the degree of suffering they impose on cancer patients. Depression is a leading cause of disability or suicide attempts in the worldwide. Prevalence rates of depression among cancer patients can be as high as $38 \%$ for major depression and $58 \%$ for depression spectrum syndromes. ${ }^{5}$ Ideally, all cancer patients should be screened for depression in the clinic upon their first visit and on a regular basis thereafter by their oncologist, especially when changes occur in their disease status (remission, recurrence, progression of disease, etc.). ${ }^{5}$ The incidence of depression is rising worldwide, possibly due to urban crowding and insufficient resources. This pandemic raises the possibility that disabling depression among patients with cancer will increase. Already, about one-third of patients with cancer present with depression. Although many progressive cancer centers are instituting psycho-oncology services, the limited numbers of psychiatrists in the coming decade suggests that these programs may flounder unless nurses can provide adjuvant support. Nurses can provide the psychosocial care for cancer patients may lead to relieving emotional distress and promoting well-being then improve their quality of lives. After diagnosis, patients will be referred to a mental health professional for psychological/psychiatric evaluation to prevent depression. ${ }^{6}$ Therefore, this study was conducted to assess the level of depression among cancer patients in Nanakaly Hospital, Erbil city, Iraq and find out the association between demographic characteristics of the studied sample and their depression levels.

\section{Methods}

This cross-sectional study was conducted between February $22^{\text {nd }}, 2016$ and April $27^{\text {th }}, 2016$ on 100 cancer patients in Nanakaly Hospital, Erbil City of Kurdistan Region, Iraq. A non-probability purposive sample was selected. The sample was selected according to the following inclusion criteria: patients having all types of cancer, patients should answer verbally, adult, both genders. Exclusion criteria: None verbally and anybody refuse participation. Data were collected by same researcher using interview technique in the Kurdish language. Each interview lasted 20 minutes, the questionnaire is comprised of two parts, Part-I-Socio-demographic characteristics include age, gender, marital status, level of education, residence, occupation, Religion and medical status of patient include cancer type and chronic diseases and part- II- depression Scale, The Beck depression rating inventory which includes 18 questions and each question has 3 responses that are ranked from 0 to 2 and the patient's selects one response that is more suitable for his or her emotional state. It also observes depression level as the following: $0-9$ normal range, 10-18 mild depression level, 19-27 moderate depression level and 2836 severe depression level "this instrument has validity and reliability which is done by Gardi A. (2009). ${ }^{7}$ The ethical approvals for conducting this study was approved obtained from the ethical committee in College of Nursing, Hawler Medical University. Data were analyzed through using the statistical package for the social sciences (version 22) performed using descriptive statistical data analysis approach; such as frequencies, percentages, and inferential statistical data analysis approach which is presented as Chi-Square test, all statistical procedures were tested on a probability of $P$ value and divided as follows:

$\leq 0.01$ highly significant

$\leq 0.05$ significant

$>0.05$ non-significant. $^{8}$ 


\section{Results}

Table 1 shows that $46 \%$ of participants were in the age group 41-63 years old. The mean age \pm SD of the participants was $49.54 \pm 16.66$. Each of males and females represented $50 \%$ of the sample. Most of the participants were married $(75 \%)$, illiterate (35\%), Muslims (94\%), housewives $(38 \%)$, had somehow sufficient income $(40 \%)$ and from rural areas (84\%).

Table 1: Socio-demographic characteristics of the patients $(N=100)$.

\begin{tabular}{|c|c|c|c|}
\hline \multicolumn{2}{|c|}{ Socio-demographic data } & \multirow{2}{*}{$\begin{array}{c}\text { No. } \\
29\end{array}$} & \multirow{2}{*}{$\begin{array}{l}\frac{\%}{29} \\
2\end{array}$} \\
\hline \multirow{3}{*}{ Age group (years) } & $18-40$ & & \\
\hline & $41-63$ & 46 & 46 \\
\hline & 64 and above & 25 & 25 \\
\hline \multicolumn{4}{|c|}{ Mean and SD $=49 \cdot 5 \cdot 16 \cdot 66 \pm 4$} \\
\hline \multirow[t]{4}{*}{ Gender } & Male & 50 & 50 \\
\hline & Female & 50 & 50 \\
\hline & illiterate & 35 & 35 \\
\hline & able to read and write & 11 & 11 \\
\hline \multirow{3}{*}{ Level of education } & primary school graduate & 18 & 18 \\
\hline & secondary school graduate & 14 & 14 \\
\hline & preparatory school graduate & 11 & 11 \\
\hline \multirow{3}{*}{ Patient's occupation } & institute and college graduate & 11 & 11 \\
\hline & Employed & 34 & 34 \\
\hline & Housewife & 35 & 35 \\
\hline \multirow{4}{*}{ Marital status } & Unemployed & 15 & 15 \\
\hline & Retired & 16 & 16 \\
\hline & Single & 18 & 18 \\
\hline & Married & 75 & 75 \\
\hline \multirow[b]{2}{*}{ Religion } & Widow/widower & 7 & 7 \\
\hline & Muslim & 94 & 94 \\
\hline \multirow{3}{*}{ Economic Status } & Christian & 6 & 6 \\
\hline & Sufficient & 22 & 22 \\
\hline & Somehow sufficient & 40 & 40 \\
\hline \multirow{3}{*}{ Residential area } & Insufficient & 38 & 38 \\
\hline & Rural & 84 & 84 \\
\hline & Urban & 16 & 16 \\
\hline
\end{tabular}


Table 2 shows the medical status of Table 3 shows the occurrence of severity the patients; more than half $(55 \%)$ of the studied sample suffered from blood disease cancers. and hypertension was the most common disease among the $35 \%$ patients with chronic diseases. levels of depression among patients as estimated that, $79 \%$ and $21 \%$ of them suffered from moderate depression and severe depression levels respectively.

Table 2: Medical status of the patients $(\mathrm{N}=100)$.

\begin{tabular}{|c|c|c|}
\hline Medical information on the patients & No. & $\%$ \\
\hline \multicolumn{3}{|l|}{ Types of cancers } \\
\hline Blood Disease & 55 & 55 \\
\hline Others & 45 & 45 \\
\hline \multicolumn{3}{|l|}{ Chronic Disease } \\
\hline Yes & 35 & 35 \\
\hline No & 65 & 65 \\
\hline Hypertension & 14 & 14 \\
\hline Diabetes Mellitus & 12 & 12 \\
\hline Ischemic Heart Disease & 3 & 3 \\
\hline Hypertension and Diabetes Mellitus & 6 & 6 \\
\hline
\end{tabular}

Table 3: Severity levels of depression among patients ( $N=100)$.

\begin{tabular}{lcc}
\hline Levels of depression & No. & $\%$ \\
\hline Moderate depression level & 79 & 79 \\
Severe depression level & 21 & 21 \\
Total & 100 & 100 \\
\hline
\end{tabular}


Table 4 demonstrates the association significant association between the level between the socio-demographic characteristics of patients and levels of depression. In general, there was no of depression and their socio-demographic characteristics.

Table 4: Association between socio-demographic characteristics of patients and levels of depression $(\mathrm{N}=100)$

\begin{tabular}{|c|c|c|c|c|c|c|c|}
\hline \multirow{3}{*}{\multicolumn{2}{|c|}{ Socio-demographic }} & \multicolumn{4}{|c|}{ Levels of depression } & \multirow{3}{*}{ Total } & \multirow{3}{*}{$P$ value } \\
\hline & & \multicolumn{2}{|c|}{$\begin{array}{l}\text { Moderate } \\
\text { depression }\end{array}$} & \multicolumn{2}{|c|}{$\begin{array}{c}\text { Severe } \\
\text { depression }\end{array}$} & & \\
\hline & & No. & $\%$ & No. & $\%$ & & \\
\hline \multirow[t]{3}{*}{ Age group } & $18-40$ & 22 & 75.86 & 7 & 24.14 & 29 & \multirow{3}{*}{0.754} \\
\hline & $41-63$ & 36 & 78.26 & 10 & 21.74 & 46 & \\
\hline & 64 and above & 21 & 84 & 4 & 16 & 25 & \\
\hline \multirow[t]{2}{*}{ Gender } & Male & 38 & 76 & 12 & 24 & 50 & \multirow[b]{2}{*}{0.312} \\
\hline & Female & 41 & 82 & 9 & 18 & 50 & \\
\hline \multirow{6}{*}{$\begin{array}{l}\text { Patient's } \\
\text { education }\end{array}$} & Illiterate & 30 & 85.71 & 5 & 14.29 & 35 & \multirow{6}{*}{0.502} \\
\hline & Able to read and write & 10 & 90.1 & 1 & 9.9 & 11 & \\
\hline & Primary school graduate & 12 & 66.67 & 6 & 33.33 & 18 & \\
\hline & $\begin{array}{l}\text { Secondary school } \\
\text { graduate }\end{array}$ & 10 & 71.42 & 4 & 28.58 & 14 & \\
\hline & $\begin{array}{l}\text { Preparatory school } \\
\text { graduate }\end{array}$ & 9 & 81.81 & 2 & 18.19 & 11 & \\
\hline & $\begin{array}{l}\text { Institute and college } \\
\text { graduate }\end{array}$ & 8 & 72.7 & 3 & 72.3 & 11 & \\
\hline \multirow{4}{*}{$\begin{array}{l}\text { Patient's } \\
\text { Occupation }\end{array}$} & Employed & 30 & 85.71 & 5 & 14.29 & 35 & \multirow{4}{*}{0.478} \\
\hline & Retired & 12 & 75 & 4 & 25 & 16 & \\
\hline & Unemployed & 10 & 66.67 & 5 & 33.33 & 15 & \\
\hline & Housewife & 27 & 79.41 & 7 & 20.59 & 34 & \\
\hline \multirow{3}{*}{$\begin{array}{l}\text { Marital } \\
\text { status }\end{array}$} & Single & 13 & 72.22 & 5 & 27.78 & 18 & \multirow{3}{*}{0.611} \\
\hline & Married & 61 & 81.33 & 14 & 18.67 & 75 & \\
\hline & Widow/widower & 5 & 71.42 & 2 & 28.58 & 7 & \\
\hline \multirow{3}{*}{$\begin{array}{l}\text { Economic } \\
\text { Status }\end{array}$} & Sufficient & 18 & 81.81 & 4 & 18.19 & 22 & \multirow{3}{*}{0.923} \\
\hline & Somehow sufficient & 31 & 77.5 & 9 & 22.5 & 40 & \\
\hline & Insufficient & 30 & 78.94 & 8 & 21.06 & 38 & \\
\hline \multirow{2}{*}{$\begin{array}{l}\text { Residential } \\
\text { area }\end{array}$} & Rural & 69 & 82.14 & 15 & 17.86 & 84 & \multirow[b]{2}{*}{0.077} \\
\hline & Urban & 10 & 62.5 & 6 & 37.5 & 16 & \\
\hline \multirow[t]{2}{*}{ Religion } & Muslim & 75 & 79.79 & 19 & 20.21 & 94 & \multirow{2}{*}{0.444} \\
\hline & Christian & 4 & 66.67 & 2 & 33.33 & 6 & \\
\hline
\end{tabular}


Table 5 shows that there were no statistically significant differences between the medical status of patients and level of depression.

\section{Discussion}

The findings of the present study indicate that majority of the studied sample was in the age group 41-63 years old. This result was compatible with the results of a study conducted in Turkey, which indicated that most of the participants were less than 50 years old. ${ }^{9}$ The highest percentage of the sample was illiterate similar to the research that was carried out in Iran. ${ }^{10}$ The majority of the participants were housewives, married, had somehow sufficient income, and living in rural area in coinciding with the study was carried out on 96 cancer patients in Turkey, showed that the majority of participants were married, housewife, moderate level of economic status. ${ }^{11}$ Our explanation for these results of the present study is that the educational level affects patient's depression level, the illiterate patients have high depression level than the educated patients. Patients who are not working reported significantly more depression level than worker patients, the reason for this result is workers patients are busy and they have a little time for thinking about the disease. Cancer patients lived in rural areas have a high level of depression than cancer patients lived in urban areas, this result may be because of most of our sample are illiterate, little information they have about cancer and the distance between the rural areas and the hospital was too far. All these reasons may be lead to higher level of depression. Results of the present study showed that the occurrence of severity levels of depression was in moderate level among the majority of patients with cancer, the results were similar to the results of a study conducted in Turkey and Nepal as reported that cancerous patients experience moderate levels of de-pression. ${ }^{11,12}$ However, the results of our study were in disagreement with the results of another study that was carried out on 809 cancer patients in Columbus, which found that a large proportion of cancer patients had high levels of depression. ${ }^{13}$ Such disagreement might be due to the difference in questionnaire tool, sample size and culture. Depression was the main psychological problem in cancer patients because its prevalence was markedly higher than that of anxiety. ${ }^{9}$ The percentages of cancerous patients with depression as reported by various studies ranged from 25 to $54 \%$. ${ }^{14-17}$ On the other hand, may be due to the side effects of chemotherapy treatment and change in body image by surgical intervention.

Table 5: Association between medical status of patients and levels of depression $(N=100)$.

\begin{tabular}{lccccccc}
\hline \multirow{2}{*}{ Medical status } & \multicolumn{7}{c}{ Levels of depression } \\
& \multicolumn{2}{c}{$\begin{array}{c}\text { Moderate } \\
\text { depression }\end{array}$} & $\begin{array}{c}\text { Severe } \\
\text { depression }\end{array}$ & Total & $\boldsymbol{P}$ value \\
& No. & $\%$ & No. & $\%$ & & \\
\hline Types of cancers & Blood Disease & 42 & 76.37 & 13 & 23.63 & 55 & 0.474 \\
& Others & 37 & 82.22 & 8 & 17.78 & 45 & \\
Hypertension & 12 & 85.71 & 2 & 14.29 & 14 & \\
Diabetes Mellitus & 9 & 75 & 3 & 25 & 12 & \\
Ischemic Heart Disease & 2 & 66.67 & 1 & 33.33 & 3 & 0.932 \\
Hypertension and Diabetes Mellitus & 5 & 83.33 & 1 & 16.67 & 6 & \\
No chronic disease & 51 & 78.47 & 14 & 21.53 & 65 & \\
\hline
\end{tabular}


The results of the present study indicated that there was no significant association between the level of depression and the patient's socio-demographic characteristics. These results were similar to the study conducted in Babylon city in Iran, reported that there were no significant relationships between depression and gender, marital status and the educational levels of the patients. However, significant relationships had been noted between depression and the age group of the patients in a higher frequency in older ages. ${ }^{10}$ Another study conducted on the prevalence of anxiety and depression among 716 evaluable patients in Norwegian reported that age or gender had no influence on the occurrence of depression. ${ }^{18}$ The results of the current study reported that there was not a significant association between patient's level of depression and medical status of patients such as types of cancer, chronic diseases include hypertension, diabetes mellitus, and ischemic heart disease, similar results were observed in a study conducted in Babylon city in Iraq. ${ }^{3}$

\section{Conclusion}

The study concluded that the majority of the patients with cancer had a moderate depression. There was no significant association between patient's socio-demographic characteristics and depression level. It is recommended to improve the psychological and emotional status for cancer patients of all types, especially by nursing staff after taking chemotherapy treatment. Coordination between oncology hospitals and psychiatry hospitals is needed to give treatment to reduce depression level. Early detection of the signs and symptoms of depression by nurses is necessary to prevent worsening of the depression level. Conducting similar studies at the national level on the largest sample to assess depression among cancer patients.

\section{Conflicts of interest}

The authors report no conflicts of interest.

\section{References}

1. Winell J, Roth AJ. Depression in cancer patients. Department of Psychiatry and Behavioral Sciences. Memorial Sloan-Kettering Cancer Center, New York; 2004.

2. Takashi H, Takayuki A. Depression among cancer patients. PCNJ 2008; 50:6-17.

3.Burhan $\mathrm{H}$, Intesar A. Assessment of Depression among Cancer Patients in Babylon City. Kufa Journal for Nurses Sciences 2016; 1:5.

4. Samit P, Pankaj K, Bhatia M. Depression in Cancer Patients. DPJ 2010; 13:2

5. Trill MD. Psychological aspects of depression in cancer patients: an update. HAOMOJ 2012; 23:10-302.

6. Paul BJ, Heather SJ. Psychosocial Interventions for Anxiety and Depression in Adult Cancer Patients: Achievements and Challenges. CAACCJ 2008; 58:214-30.

7. Gardi A. Impact of psycho-educational program on the psychological distress of infertile women attending the infertility center in Hawler city. PhD. dissertation. Hawler Medical University, College of Nursing; 2009.

8. Maltby J, Day L, Williams, G. Introduction to statistic for nurses. $1^{\text {st }}$ ed. UK, Go Sport Publishing; 2007. p.115.

9. Hong JS, Tian J. Prevalence of anxiety and depression and their risk factors in Chinese cancer patients. Support Care Cancer J 2014; 22:453-9.

10. Nikbakhsh N, Moudi S, Abbasian S, Khafri S. Prevalence of depression and anxiety among cancer patients. Caspian J Intern Med 2014; 5(3):167-70.

11. Elanur Y Karabulutlu, Mehmet Bilici, Kerim Çayır, Salim Başol Tekin, Ragibe Kantarc. Coping Anxiety and Depression in Turkish Patients with Cancer. Eur J Gen Med 2010; 7(3):296-302.

12. Thapa P, Rawal N, Bista Y. A study of depression and anxiety in cancer patients. NMCJ 2010; 12(3):171-5.

13. Carroll BT, Kathol RG, Noyes R Jr, Wald TG, Clamon $\mathrm{GH}$. screening for depression and anxiety in cancer patients using the Hospital Anxiety and Depression Scale. GHPJ 1993; 15:(2):69-74.

14. Massie MJ. Prevalence of depression in patients with cancer. Natl Cancer Inst Monogr J 2004; 32:57-71.

15. So WK, Marsh G, Ling WM, Leung FY, Lo JC, Yeung $M$, et al. Anxiety, depression and quality of life among Chinese breast cancer patients during adjuvant therapy. Eur J Oncol Nurs 2009; 14:17-22.

16. Strong V, Waters R, Hibberd C, Rush R, Cargill A, Storey D, et al. Emotional distress in cancer patients: the Edinburgh Cancer Centre symptom study. Br J Cancer 2007; 96:868-74. 
17. Ashraff S, Gupta AK, Chaudhury S, Sudarsanan S, Raju MSVK, Salujha SK, et al. Effect of short-term psychiatric intervention in cancer patients. MJAFI 2004; 60:109-12.

18. Aass N, Fosså SD, Dahl AA, Moe TJ. Prevalence of anxiety and depression in cancer patients seen at the Norwegian Radium Hospital. ECJ 1997; 33(10):1597-604. 